\title{
CIMARRONAJE DE CHINOS
}

\author{
CIMARRONAJE OF CHINES PEOPLE
}

Wilfredo Kapsoli Escudero ${ }^{1}$

\section{RESUMEN}

Durante la sociedad medieval en Europay en el mundo colonial americano la palabra cimarrón, era el nombre con que se asignaba al ganado que vivía libre en los campos y alturas fuera de la ciudad. Cada cierto tiempo, generalmente al año, los dueños iban a recuperar estos animales en una práctica conocida como rodeo 0 chaco. Este concepto fue endilgado a los esclavos fugitivos de las haciendas y obrajes y posteriormente a los semi esclavos chinos. Estos hombres huían de los maltratos y explotación a que eran sometidos por los dueños de las plantaciones o ingenios azucareras y algodoneros. Ellos se convertían en bandoleros y en ocasiones formaban palenques (tierra liberada). Durante el siglo XIX los chinos cimarrones fueron motivo de cacerías y de rescate para el retorno a sus lugares de trabajo recibiendo mayor maltrato que recibían antes de la huída.

Palabras clave: Bandoleros, cimarrones, obrajes, palenques, plantaciones, semi esclavos.

\section{ABSTRACT}

During medieval society in Europe and in the American colonial world, the word cimarron was the name given to livestock that lived free in the fields and heights outside the city. From time to time, usually a year, the owners would recover these animals in a practice known as rodeo or chaco. This concept was given to the fugitive slaves of the haciendas and obrajes and later to the semi Chinese slave. These men fled from the mistreatment and exploitation to which they were subjected by the owners of plantations or sugar and cotton mills. They became bandits and sometimes formed palenques (liberated land). During the nineteenth century the cimarron Chinese were the cause of hunts and rescue to return to their places of work, receiving more abuse tha the one received before the escape.

Keywords: Bandoleros, maroons, obrajes, palenques, plantations, semi slaves.

\section{INTRODUCCIÓN}

En la historia de las sociedades subalternas, en muy pocas ocasiones se ha tratado del tema del Cimarronaje sean estos esclavos negros o coolies chinos. Los intelectuales cubanos han mostrado gran interés por tal cuestión, de modo que conocemos estudios extensos sobre el mismo. Para el caso peruano hay menos referencias y particularmente la vida de los coolies chinos en dicha condición de cimarrones son poco investigados. Humberto Rodríguez Pastor es uno de los primeros en referirse a dicho problema.

Cuando estudiamos el tema de la esclavitud negra en el Perú, encontramos que una de las modalidades de esta gente para poder ponerse a salvo de la explotación que sufrían al interior de las haciendas, era huir de ellas, ponerse al margen y convertirse en hombres libres, vagabundear, formar partidas de bandoleros, es decir, lo que entonces se llamaba convertirse en cimarrones. Esta situación de los esclavos ha sido tratada con cierta frecuencia, especialmente en Cuba, Venezuela donde la población esclava fue preponderante y donde los negros huidos llegaron prácticamente a tener un papel significativo en la sociedad rural de estos países; sin embargo, casi hasta donde se tenga información no ha sido preocupación de los estudiosos. El fenómeno del cimarronaje para el caso de los chinos, trabajadores que en condición de contratados venían enganchados de sus lugares de origen para cumplir una contrata de 8 años y en la práctica llegaron a utilizar los mismos galpones, las mismas condiciones en el uso de la tecnología como en los procesos productivos que antes habían realizado los esclavos negros y que ahora los chinos los reemplazan después de que fueron liberados por Ramón Castilla, en 1854.

Revisando la documentación de algunas haciendas, especialmente la de Cayaltí, los informes de las prefectu-

\footnotetext{
'Doctor en Letras e Historia. Autor de los libros: Nacionalismo Inca, Modernidad y tradición peruana, César Vallejo en la crítica internacional, entre otros. Actualmente es docente en la Universidad Ricardo Palma, Lima - Perú. E-mail: wckapsoli@ hotmail.com
}

Presentado: 03/04/17 Aprobado: 16/05/17 
ras y sub-prefecturas, periódicos y documentos para hacer el estudio de los movimientos populares en el Perú en el siglo XIX, que fue publicado por la Editorial Mejía Vaca, en la colección de Historia General del Perú en el tomo XII, pudimos observar con cierta sorpresa, que este problema del cimarronaje también había sido un aspecto de especial significación e importancia durante la presencia de los trabajadores chinos en las haciendas, en la construcción de los ferrocarriles o en la explotación del guano de las islas.

En general, no se tiene una cifra exacta de los chinos que llegaron al país, existe una larga discusión sobre la cantidad de estos trabajadores que habrían arribado al Perú desde 1840 hasta después de la guerra con Chile, precisamente, se hará un cotejo de las distintas cifras que manejan historiadores cubanos e historiadores nacionales para luego presentar quizá un punto que podría ser casi el promedio; pero lo cierto, es que se puede observar momentos iniciales en que la captura y la traída de los chinos fue más bien de zonas distintas a la del Imperio Celeste, fue de la zona de los polinesios, cuyas modalidades de absorción han sido descritas por Juan de Arona y también aparecen comentadas en la tesis de Vilma Derpich.

Como esta modalidad fue tan primitiva y brutal motivo de condena y en buena cuenta una suspensión temporal de esta inmigración de los chinos; más adelante, se formalizó nuevamente y la inmigración fue de preferencia de las zonas de Macao, Canton, lugares muy pobres con una gran población campesina china y que eran pues motivo de todos los que se dedicaban al tráfico y a la trata de los chinos.

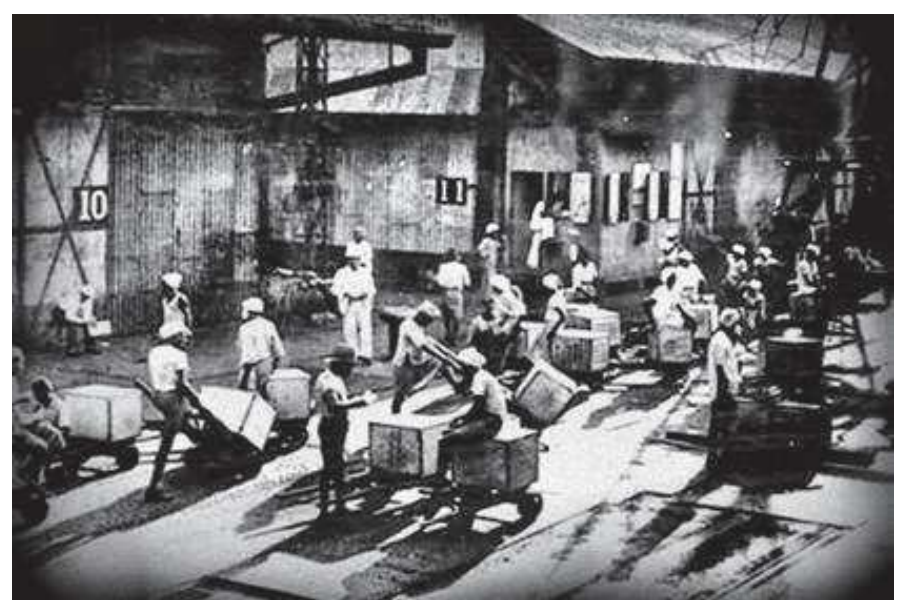

Figura 1. Chinos trabajando en una hacienda, sufrían explotación y falta de alimento

Al analizar, varios momentos y regiones donde se produjo el fenómeno del cimarronaje, se tiene información como en el caso del Valle de Chicama, donde los trabajadores de las haciendas Chiquitoy, Chicamita y Pampas, fueron prófugos y se pusieron fuera del control de los propietarios.

Igualmente, para el caso de algunas haciendas del Valle de Lambayeque, especialmente, la de Pátapo, Pucalá, Cayaltí e igualmente otras de la zona de Pacasmayo, por ejemplo, la hacienda Lurifico. Para el caso de Lima, encontramos un expediente en el que 38 asiáticos fugaron de la hacienda Monterrico, siendo estos capturados. Se inició un proceso sumamente interesante, en el que cada uno de los chinos fueron presentando las razones de su fuga. El patrón y quiénes controlaban la hacienda decían que los chinos eran viciosos, que trabajaban siempre contra su voluntad, que eran inclinados al ocio, y, por tanto, esta era la razón por la cual vagabundean.

Por el contrario, los propios protagonistas declaraban, por ejemplo, Akao, que el mayordomo les había propinado 150 azotes y hasta le quitaron el alimento suficiente, lo pusieron en prisión, de modo que en la primera oportunidad que tuvo se fugó. Otro chino, Afo, procedente de Cantón, soltero de 20 años decía que no le pagaban su salario, que trabajaba día y noche cuidando el riego del agua y que le habían dado más de 100 azotes por lo que optó por la fuga, otro chino, Ayana, también de Cantón, soltero de 30 años igualmente cuidaba el riego de las chacras recibió 120 azotes, que no le daban su jornal, que trabajaba día y noche y algunas veces incluso lo tenían en el trabajo con cadenas y 
asílos otros chinos van presentando sus quejas.

Este episodio de fuga sucedió en 1861, el dueño de la hacienda era don Francisco Ricardo Menéndez, lo significativo de esta contienda es que los chinos no querían regresar a la hacienda y algunos fueron puestos en calidad de confinados o depositados en una panadería llamada de las Nazarenas donde permanecerían hasta que terminara el juicio, otros reclamaban que los contratos que tenían ya habían concluido de modo que pedían se declare en libertad. Justamente, a partir de esta situación contenciosa se pudo observar que de acuerdo a las contratas que suscribía el trabajador colie con el hacendado, se precisaba de manera exprofesa que los días de la huida no serían contados para los fines del cumplimiento de la contrata de los 8 años, pero sobre todo, los gastos que hubiera ocasionado a la hacienda, el proceso de persecución y captura con la participación de gente especializada en esta tarea serían cargado a cuenta o deuda del chino, de modo que en buena cuenta una fuga de algunos días, para un chino, su recaptura significaba a la larga extender su situación dependiente en la hacienda durante mucho tiempo. Se ha podido copiar, a manera ilustrativa, algunos casos donde se puntualiza justamente esta situación.

Por ejemplo, se cita que en la liquidación de contratas del asiático Afo, se dice entre líneas que se había "cimarroneado repetidas veces", luego se indica que cuando estuvo prófugo que fue por 3 años se le tuvo que cargar los gastos por aprehensión por la contrata de 9 bestias a 6 pesos cada uno y dos individuos a 8 pesos cada uno, que distribuidos entre los siete le toca a este diez pesos o sea se habían fugado entonces con otros 7 chinos que debiéndolos pagar con aumentos de servi- cios, se calcula 4 meses para cortar según su contrata los 30 pesos de cada año.

El caso del chino Akao, que habiéndose cimarroneado dos veces se cargan los 5 meses que estuvo la primera y dos la segunda que son 7 meses; se traspasó la contrata que celebró con el Sr. Elgur, la segunda vez, que se cimarroneó que fue por 3 años, que principiaron también en julio de 1858. Y en relación al chino Ajó, se indica también que habiéndose cimarroneado a principios de febrero de 1858 solo sirvió 2 años y finalmente en el caso del chino Yana fue comprado en mayo de 1856 por José Fernández, "que me lo traspasó por cimarrón en el año 1858, por el tiempo que faltaba para cumplir su contrato".

Como se ve, en este fenómeno del cimarronaje, la huida parece que fue bastante grande, generalizado y se dio en distintos lugares donde si existían los chinos, los cimarrones en algunos casos, llegaron a formar palenques (territorios libres), que es una categoría bastante importante, prácticamente también inédito en la investigación de este tema de los chinos y se ha encontrado, por ejemplo, referencias de que en Lima, por el fundo Chavarría existía un palenque de asiáticos cimarrones. Para el caso de la zona norte en Lambayeque, también se hace referencia, donde el hacendado dice lo siguiente: "no tenemos sino Alén que perseguido con actividad se refugió en los huertos y la hacienda Capote y por falta de buena voluntad del administrador de ese fundo no pudo ser cogido, lo de siempre en esa hacienda que es un palenque de cimarrones, el chino Hacen Cantones, prófugo desde agosto de 1875 después de habérselo puesto en la cárcel".

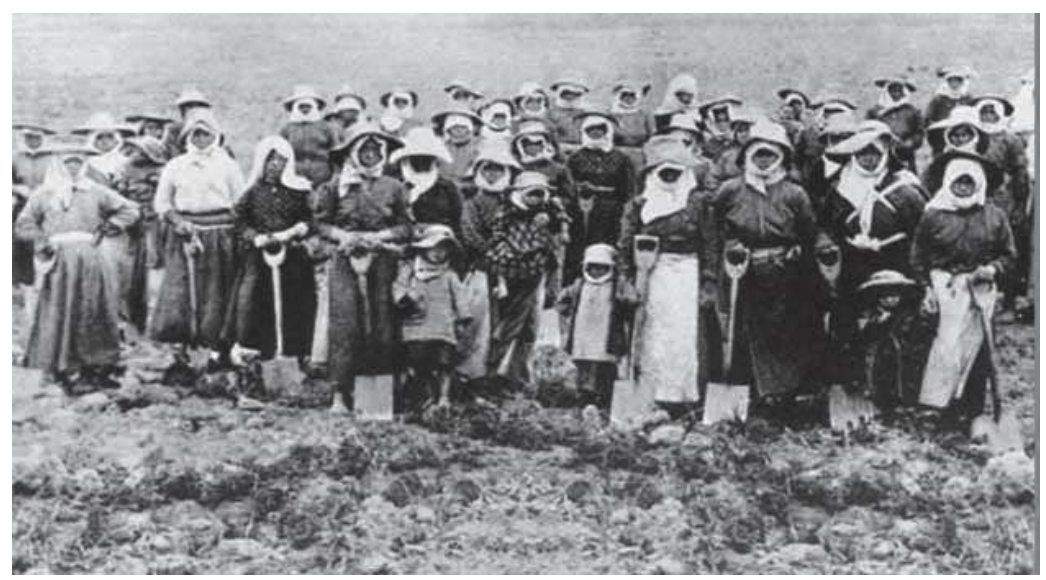

Figura 2. Chinos al final de la faena laboral, no tenían descanso por lo que se veían obligados a huir 
En la formación de palenques, en realidad, no ha sido posible desentrañar cuáles eran sus particularidades de estructura de organización de funcionamiento; en todo caso, se conoce los palenques que formaron los negros y eran en realidad una suerte de territorios libres donde los esclavos reproducían y afianzaban su identidad cultural, era una forma prácticamente de escapar a los procesos de deculturación que el sistema generaba con ellos. Es decir para el caso de los esclavos no solamente interesaba al amo, tener materialmente la posesión de esta persona, sino también para lo espiritual, para hacerles lavado cerebral, de tal manera, que todos sus valores ancestrales, su idioma, cultura, idiosincrasia, religión, sea reemplazado por la cultura hispana, ponerse a salvo totalmente de este contagio ideológico y de esta dominación mental significaba a la larga el palenque, aunque obviamente antes de esto significaba ponerse a salvo a la explotación.

En el caso de los chinos, hay la referencia de que se formaron palenques de chinos, pero la documentación que a la fecha, se ha podido ubicar, no nos dice más acerca de esta institución. Los otros chinos cimarrones, devenían probablemente en bandoleros, vagabundos, tampoco hemos podido encontrar referencias específicas, de partidas de bandoleros o movimientos de abigeos o salteadores de caminos que haya sido protagonizado por los chinos, parece que en todo caso, la situación de ellos era bastante difícil porque como vinieron prácticamente solo hombres y por su particular contextura étnica y racial en buena cuenta no podían ponerse a salvo de sus perseguidores, porque donde vaya al chinito lo reconocían y no contaron en ningún caso, con el apoyo de población ya sea india o mestiza que se solidarizara con ellos. En todo caso, incluso este fenómeno de cimarronaje fue alentado hasta por los propios hacendados y contratistas, quienes capturaban o facilitaban a los chinos fugarse de una hacienda para contratarlos a otros o traspasarlos, entonces, prácticamente se diría que existía un mercado negro de venta de contratos de chinos. Hay algunos documentos que describen de ciertos chinos procedentes de otro lugar, como Lima, fueron encontrados o tomados antes de que partieran a zonas del norte, específicamente Chicama, Trujillo y Chimbote, por contratistas exprofesamente preparados.

La huida de los chinos de la hacienda o de la explotación guanera, sobre esta última, hay una descripción registrada por un viajero, donde patéticamente se presentan las condiciones infrahumanas, en las que se encontraban estos trabajadores, habría que señalar de que era en esencia, por las condiciones de explotación que sufrían en las haciendas, el maltrato, la esclaviza- ción. Algunos ejemplos: lo vamos a precisar para los casos de la hacienda Cayaltí y la hacienda Palto, dos haciendas de los Aspíllaga, para los cuales, se cuenta con una documentación.

Y también para el caso de Palto tenemos, un reglamento interno donde se marcaban las disposiciones y las normas que los chinos debían cumplir tanto antes del trabajo, como después de él, es decir, un reglamento interno de funcionamiento del laboreo de los chinos. Las otras razones, que motivaba la condición del cimarronaje de los chinos, eran ciertas situaciones que precipitaban revueltas, sublevaciones. Existen informes sobre estos episodios, que terminan dando paso al cimarronaje.

Quizá una coyuntura más generalizada de este fenómeno, va a ser durante la guerra con Chile, donde prácticamente el control interno de las haciendas se relaja, el Estado se quiebra y los chinos tienen un gran papel, en tanto, que se identifican plenamente con los invasores. Los chinos piensan aquí, más en sus intereses de clase, antes que los intereses de la patria que no lo entendían, de modo que formaron batallones como el Vulcano, ejércitos totalmente formados por chinos y que vinieron en condición de guías de los chilenos, situación que ha sido bastante desarrollada por el historiador Segal.

Otra razón de la huida mucho más violenta, mucho más dramática, es el suicidio. Los chinos frente a la explotación huían de la hacienda, pero huían no solo a través del cimarronaje, sino también a través del suicidio, se ahorcaban, o generalmente consumían opio en exceso y entonces se morían. Hemos registrado varios casos de esta modalidad de resistencia por la creencia generalizada de que el suicidarse, morir en esas condiciones, implicaba resucitar en el más allá, en su tierra en el Imperio Celeste. Un factor religioso, una ansiedad de reencarnación en el futuro, propio de su filosofía oriental los impulsaba a tomar esta determinación.

Los propios hacendados, también negociaban, les vendían opio, lo hacían obviamente para fortalecerles el ánimo y disminuirles la alimentación, en buena cuenta para aumentar la productividad de los trabajadores, pero, los chinos sobrecargaban las dosis para escapar del sufrimiento. En realidad, el suicidio fue para los chinos, una especie de buscar un paraíso, ponerse a salvo del infierno terrenal, estable, permanente que constituían las haciendas, las empresas guaneras y la construcción de ferrocarriles.

Este fenómeno no se gestó en el Perú, tuvo su inicio desde el momento del enganche y la traída de los chinos, los barcos que traían gente con sobrepeso, totalmente 
por encima de su capacidad, en condiciones antihigiénicas, también con descripciones que han dejado Stewar, Vilma Derpich y otros testigos, hicieron que estas embarcaciones fueran llamadas como "los infiernos flotantes" y entonces los chinos se ponían también a salvo de estos infiernos flotantes, sublevándose en algunos casos, matando a los capitanes o conductores de la fragata, tirándose al mar o ahorcándose y muchos también morían por los efectos del viaje.

En la propia China, eufemísticamente decían a estos culies, "chanchitos viajeros". No todos murieron ni fueron cimarrones, hubo quienes se salvaron, libraron sus contratas y devinieron entonces en chinos libres. Justamente este fenómeno de chinos libres que permanecen en calidad de trabajadores de las haciendas como jornaleros o en otros casos como yanaconas, es una situación que aparece después de la guerra con Chile.

Existen fichas y testimonios, especialmente del informe de la comisión china, donde se puede apreciar una especie de geografía de chinos distribuidos en distintas regiones del país, en los cuales aparece ya el fenómeno del arrendatario y el fenómeno del colono chino, otros terminaron siendo trabajadores independientes, llegaron a formar sus fonditas, sus sitios para vender comida, sus pequeñas tiendas bodegas, es decir, el famoso chino de la esquina, es una categoría que fue acuñándose a partir de que ellos terminaban sus contratas, ya eran libres y fueron quedándose en el país.

Algunos intelectuales fueron totalmente violentos con su condena antirracista contra los chinos, como lo sustentó Clemente Palma, en su famosa tesis "Elporvenir de las razas en el Perú”, que es una clarinada meri-

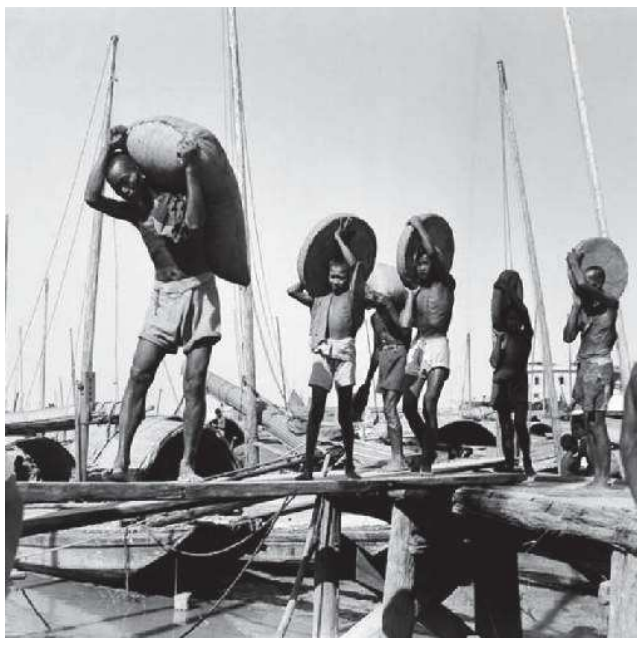

Figura 3. Chinos embarcando guano de las islas diana del racismo, quien condena prácticamente y pide el exterminio de los chinos.

Pero otro, vinculado con su propia actividad económica, es decir a los hacendados, gente que vivían a expensas del sudor de los chinos como fue el caso de Juan de Arona, llegó a decir que los chinos eran prácticamente "los chinitos de altísimo" o que eran "un don del señor" porque con el brazo, el trabajo, el sudor y la vida de esta gente fue posible mejorar la agricultura, ensanchar el latifundio, afrontar una coyuntura de auge para los productos de exportación peruano especialmente durante la guerra de secesión norteamericana, donde Estados Unidos por el conflicto no pudo abastecer a Inglaterra de algodón y otras materias primas. Estos productos se producían en países como el nuestro, asociándose la gran bonanza el guano de las islas y la riqueza generada por este producto sirvió para que los hacendados invirtieran en tecnología, mejoraran sus propiedades, de manera que este elemento de capital generado por el guano de las islas, todo ello fue revitalizado y dinamizado con los brazos y la fuerza de los trabajadores chinos. Se ha dicho y se ha hecho casi clásico el famoso comentario de que la agricultura peruana se parecía a la Venus de Nilo, una hermosa escultura, que carecía de brazos. Esta carencia de brazos fue cubierta en la época colonial hasta parte de la república hasta 1854 y tomada en posta, luego por los trabajadores chinos que cumplieron una larga, penosa pero importante contribución a nuestra economía, a nuestra cultura y a nuestra historia.

\section{REFERENCIAS BIBLIOGRÁFICAS}

Choy, E. (2015). La servidumbre china en el Perú (comentario bibliográfico) Lima, Ed. URP.

Derpich, V. (1999). Empresarios chinos en el Perú. Lima, Ed. Congreso del Perú.

Kapsoli, W. (1988). Ensayos de nueva historia. Lima, Ed. Francisco Gonzáles.

Kapsoli, W. (2015). Espejo Chino en el Perú. URP.

Rodríguez, H. (2000). Herederos del dragón. Lima, Ed. Congreso del Perú.

Rodríguez, H. (1999). Chinos Cimarrones en Lima. Investigaciones Sociales. Universidad Nacional Mayor de San Marcos. 